\title{
Mental Health Literacy of University Students
}

\author{
Rachella Ryandra Fitri1 \\ ${ }^{1}$ Department of Psychology, Universitas Negeri Yogyakarta, \\ Jl. Colombo No. 1 Karang Malang Sleman, Yogyakarta \\ ${ }^{1}$ rachella.ryandra2015@student.uny.ac.id
}

\begin{abstract}
The purpose of this study is to observe: (1) Gender difference in mental health literacy of Yogyakarta State University students and (2) Differences in mental health literacy of Yogyakarta State University students based on vignette character's gender. The type of this study was factorial survey. In this study, respondents were presented with short descriptions called vignette that were constructed and contained elements that had been manipulated by the researcher to control certain variables, namely gender and mental disorders that the characters had. Then, subjects were asked to answer closed questions (Mental Health Literacy Test) based on the vignettes. The subjects in this study were 377 undergraduate students from Yogyakarta State University. The sampling techniques used in this study were cluster random sampling and incidental sampling. Chi-Square was performed to analyze the data. The results of this study indicated that: (1) There were gender differences in mental health literacy aspect positive attitudes toward professional help where more male respondents did not recommend seeking professional help for depression (2) There were differences in mental health literacy aspects knowledge about the causes of mental disorders and positive attitudes towards professional help based on gender vignette characters for depression.
\end{abstract}

Keywords: Mental health literacy; university student; gender differences

\section{Introduction}

Mental health literacy is defined as knowledge and beliefs about mental disorders related to recognition, management, and prevention. Mental health literacy is very important for every individual to have because it is positively correlated with good mental health status (Wong, 2016), especially in an era full of demands to move more quickly and productively as it is today. The many demands cause mental health problems which are now the dominant problems in society and have an impact on the economy and emotional burden on the community.

That being said, mental health problems still have not received proper attention from the Indonesian public and its' government. According to Indonesian Basic Health Research conducted by the Indonesian Ministry of Health (2013), the prevalence of mental disorders in Indonesia is quite large, reaching 1.7 per mil or around 2 out of 1,000 residents. According to Novianty and Hadjam (2017), suicide rate in Indonesia also continues to increase until it reaches $1.6-1.8$ out of 100,000 residents, and the highest incidence was during the adolescent and young adult age groups (1524 years), in which one of the groups within that age range is university students.

Students are a group of young adults which are vulnerable to various mental health problems. Report from Biddle, Donovan, Sharp, and Gunnell (2007) also stated that students are also the lowest group that sought professional (formal) or social (informal) assistance for their mental health problems. University should be an ideal place for students to look for social networks and psychological health services such as counseling, but in reality, the number of students who use these health 
facilities is very low (Hunt \& Eisenberg, 2010).

Negative stigma in the campus environment is allegedly one of the reasons for why students are reluctant to associate themselves with various types of psychological assistance available within the university (Vidourek, et al., 2014; Holland \& Wheeler, 2016).

Chang (2008) and Wong (2016) asserts negative stigma around the reluctance of students to seek professional mental health assistance stems from lack of mental health literacy in the campus environment. For this reason, there is an urgency to highlight the importance of students' mental health literacy that can improve their awareness and ability to seek professional help for themselves and others to improve their psychological well-being. Reavley, McCann, and Jorm (2012) added that promotion of mental health literacy at the tertiary education level so far has received little attention, except for students in health fields such as medicine, midwifery, psychology, and so on.

Mental health literacy is a concept that was first introduced by Jorm, Korten, Jacomb, Christensen, Rodgers, and Pollitt (1997a), that consists of several components, namely:

1) ability to recognize mental disorders or psychological distress;

2) knowledge and beliefs about risk factors and causes of mental disorders;

3) knowledge and beliefs about selfhelp interventions;

4) knowledge and confidence regarding available expert assistance;

5) attitudes that facilitate recognition and appropriate search for assistance;

6) as well as knowledge about how to search for mental health information.

Mental health literacy is influenced by several factors, such as age, gender, education, culture, and personality (Furnham \& Swami, 2018). Gender is a major factor that can influence an individual's knowledge and attitude towards mental health (Holzinger, Floris, Schomerus, Carta, \& Angermeyer, 2012). Number of studies have indicated that men have lower levels of mental health literacy compared to women (Gibbons, Thorsteinsson, \& Loi, 2015; Cotton, Wright, Harris, \& Jorm, 2006; Hadjimina \& Furnham, 2017). The existence of gender differences in mental health literacy means that there are differences in early intervention, attitudes, and knowledge, which ideally should be equivalent since both men and women have risks of developing mental health problems.

Gender is a trait that is inherent in men and women that was by their culture and social environment (Fakih, 2013). Mental health problems experienced by women and men may be different due to the differences in gender construction, which can also affect their attitudes and knowledge about mental health (Wong, 2016). Women are a gender group who are more prone to mental health issues due to the stress experience related to gender expectations and lower social and financial resources. This impacts the main attention to mental health issues mainly focuses on women. Men are culturally considered to be mentally strong thus mental health problems in men are often overlooked. The existence of these gender inequality serves as reminder to include elements of gender equality in the planning, implementation and evaluation of mental health literacy programs at the national and city level (Diaz-Granados \& Stewart, 2006). These issues implore scientific community to conduct more research on gender inequality and mental health literacy. In order to get comprehensive research results, an appropriate method is needed. Leighton (2010) suggests that written vignette method has been used as a primary data 
collection tool in most studies that focus on mental health literacy.

Vignette is a method that provides brief description (scenario) about a certain situation or person (character) that was presented to the respondents to survey their assessment of the scenario (Atzmüller \& Steiner, 2010). Vignette is usually used to find out how is the level of public knowledge in recognizing common mental disorders. One important question about mental health literacy is whether the gender of people with mental disorders within the vignette can influences the respondent's literacy levels. Further investigation is needed because this problem can provide enough information related to genderspecific campaigns on mental health problems and provide better help for person with mental health problems.

\section{Methods}

\section{Research Design}

This research employs quantitative approach with factorial survey research design (also called vignette experiment). This type of research combines surveys and experimental research designs (Hox, Kreft, \& Hermkens, 1991). In factorial survey research, respondents will be presented with a number of questions based on a short description (vignette) that was constructed according to the research context. The vignette will contain elements that have been manipulated by researchers, both in the form of situations and people (characters) to control certain variables. In this study, the elements manipulated within vignette are the gender of the character and the mental disorder that the character suffered from.

\section{Participants}

The population for this study were active bachelor degree students of Yogyakarta State University, spread across 7 faculties, amounting to 27,461 students according to the data from the Ministry of
Research and Higher Education (https://forlap.ristekdikti.go.id/). Cluster random sampling was used along with incidental techniques. The clustering involved randomization of seven faculties at Yogyakarta State University into four faculties, namely: The Faculty of Education (FIP), the Faculty of Sports Science (FIK), the Faculty of Mathematics and Natural Sciences (FMIPA), and the Faculty of Language and Arts (FBS. The number of samples in this study amounted to 377 people based on Krejcie and Morgan's Table (Azwar, 2018).

\section{Research Procedure and Intruments}

In this study, participants were presented with a short description (vignette) about a person with depression and a person with schizophrenia as well as mental health literacy test. Both mental disorders for the vignette were chosen based on the most prevalent mental disorders in Indonesian society (Ministry of Health, 2016). Whereas, the Mental Health Literacy Test was used to reveal the respondent's ability to recognize, identify the cause, and recommend the assistance of a mental health expert on a given vignette. The Mental Health Literacy Test was developed by referring to the test used by Jorm, et al. (1997a).

Recognition of mental disorders in men and women projected by vignette characters have experienced gender manipulation, namely men and women by dividing the vignette into two versions, one is a man named Budi (Pseudonym) and one female named Bunga (Pseudonym). Each participant will be randomly given a vignette with either a male or female character, the participants was then asked to answer a Mental Health Literacy Test based on the vignette that they previously read. The questions presented within the vignette aimed to measure three aspects of mental health literacy: ability to recognize, identify the cause, and recommend the assistance of a mental health expert. Vignette for this 
study was developed by researchers with reference to PPDGJ-III (Indonesian Guide Book for Classification of Mental Disorders version III) and studies of Farrer, et al. (2008) and Jorm, et al. (1997a) with permission from the original author. The vignette has also been validated with subject matter expert.

\section{Data Analysis}

Chi-square analysis was employed to see the differences in mental health literacy especially recognition abilities, knowledge of the causes of mental disorders, as well as positive attitudes toward expert assistance based on the respondent's gender and vignette characters (Budi for male characters and Bunga for female characters).

\section{Findings and Discussion}

\section{Participant's Characteristics}

This study involved 377 respondents, most of them are female students $(77.2 \%)$ and the rest are male students $(22.8 \%)$. Most of the respondents $(69.8 \%)$ is within the age range of 18 to 21 years old; most came from the Faculty of Education (32\%); and almost all of them have not visited a mental health professional in the past year $(91 \%)$.

Result from the Hypothesis Test

Respondents were given two vignettes about mental disorders experienced by a person (character) at random, namely depression and schizophrenia. Each depression vignette and schizophrenia have two gender-based versions of the character. Half of the participants randomly received the male version of the Vignette (50.3\%) and the rest of them $(50.7 \%)$ randomly received a female version of the Vignette.

1) Mental health literacy on depression based on respondent's gender

In the aspect of ability to recognize, a relatively small number of male respondents $(30,2 \%)$ and female respondents $(30.6 \%)$ are able to recognize depression. In the aspect of knowledge to identify the cause of mental disorders, it is revealed that stress is the most widely identified cause of depression by $65.1 \%$ of male respondents and $66.3 \%$ of female respondents. While in the aspect of positive attitudes towards mental disorders, as many as $75.6 \%$ of male respondents and $89.7 \%$ of female respondents think the vignette characters should get help from mental health experts.

Chi-square test results showed there were no differences in recognition and knowledge of the causes of depression between male and female respondents $($ pmale $=0.950$ and pfemale $=0.816 ; \mathrm{p}>$ $.05)$. However, there are differences for recommending expert assistance with female participants are slightly more likely to recommend professional help $(\mathrm{p}=.001$; $\mathrm{p} \leq .001)$.

Table 1.

Cross Tabulation and Chi-Square Results for Mental Disorders Vignette based on Respondent's Gender

\begin{tabular}{|c|c|c|c|c|c|c|c|c|c|c|c|}
\hline \multirow{4}{*}{ Aspect } & \multirow{4}{*}{ Vignette Answers } & \multicolumn{5}{|c|}{ DEPRESSION } & \multicolumn{5}{|c|}{ SCHIZOPHRENIA } \\
\hline & & \multicolumn{4}{|c|}{ Respondent's Gender } & \multirow{3}{*}{$\begin{array}{c}\chi^{2} \\
p \text {-value }\end{array}$} & \multicolumn{4}{|c|}{ Respondent's Gender } & \multirow{3}{*}{$\begin{array}{c}\chi^{2} \\
p \text {-value }\end{array}$} \\
\hline & & \multicolumn{2}{|c|}{ Male } & \multicolumn{2}{|c|}{ Female } & & & ale & & nale & \\
\hline & & $\mathrm{n}$ & $\%$ & $n$ & $\%$ & & $\mathrm{n}$ & $\%$ & $\mathrm{n}$ & $\%$ & \\
\hline Ability to & Correct & 26 & $30.2 \%$ & 89 & $30.6 \%$ & & 25 & $29.1 \%$ & 67 & $23 \%$ & \\
\hline Recognize & Incorrect & 60 & $69.8 \%$ & 202 & $69.4 \%$ & 0.950 & 61 & $70.9 \%$ & 224 & $77 \%$ & 0.251 \\
\hline
\end{tabular}




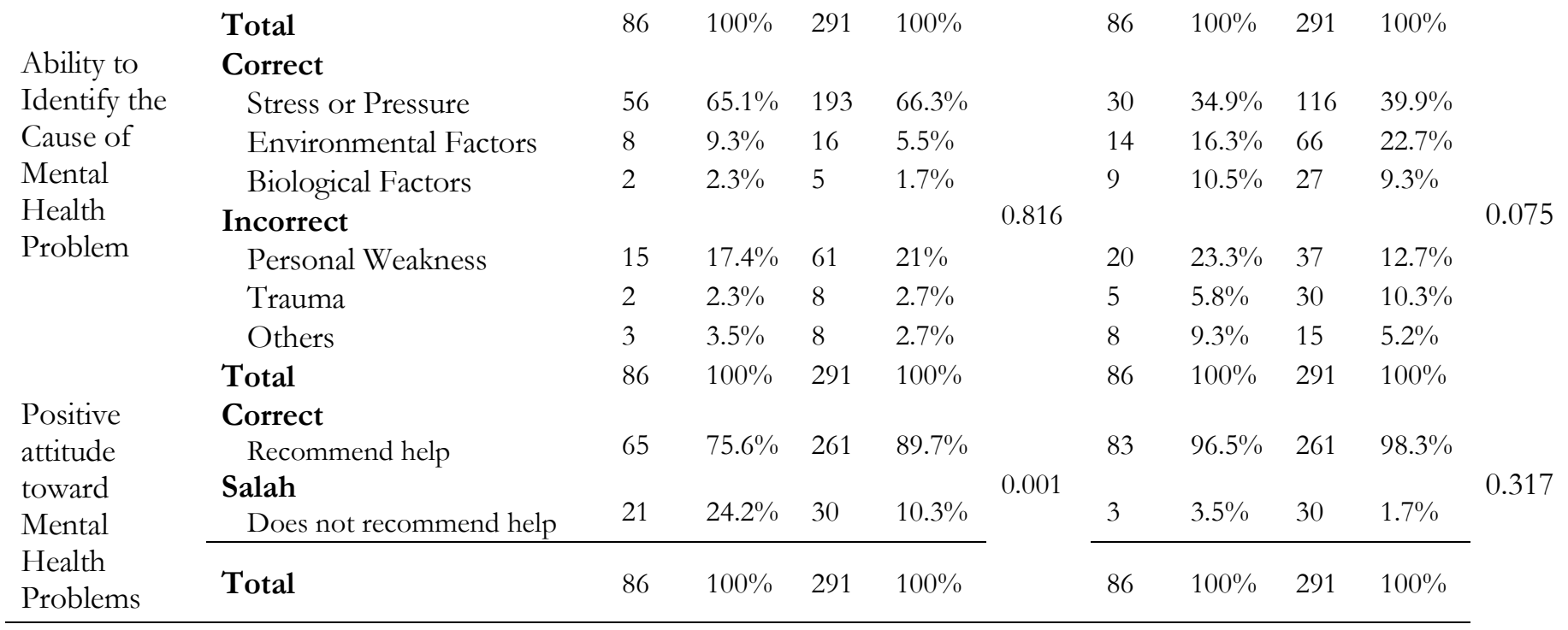

2) Mental health literacy on schizophrenia based on the respondent's gender

In the aspect of ability to recognize, a relatively small number of male respondents $(29.1 \%)$ and female respondents $(23 \%)$ are able to recognize schizophrenia. In the aspect of knowledge about mental disorders, it is known that stress is the most widely identified cause of schizophrenia by respondents, namely by $34.9 \%$ of male respondents and $39.9 \%$ of female respondents. Whereas in the aspect of positive attitude towards mental disorders, as much as $96.5 \%$ of male respondents and $98.3 \%$ of female respondents thought the characters should get help from mental health experts. Chi-square test results showed no differences in all aspects.

Table 2.

Cross Tabulation and Chi-Square Results for Mental Disorders Vignette based on Vignette Character's Gender

\begin{tabular}{|c|c|c|c|c|c|c|c|c|c|c|c|}
\hline \multirow{4}{*}{ Aspect } & \multirow{4}{*}{ Vignette Answers } & \multicolumn{5}{|c|}{ DEPRESSION } & \multicolumn{5}{|c|}{ SCHIZOPHRENIA } \\
\hline & & \multicolumn{4}{|c|}{ Character's Gender } & \multirow{3}{*}{$\begin{array}{c}\chi^{2} \\
p \text {-value }\end{array}$} & \multicolumn{4}{|c|}{ Character's Gender } & \multirow{3}{*}{$\begin{array}{c}\chi^{2} \\
p \text {-value }\end{array}$} \\
\hline & & \multicolumn{2}{|c|}{$\begin{array}{l}\text { Budi } \\
\text { (Male) }\end{array}$} & \multicolumn{2}{|c|}{$\begin{array}{c}\text { Bunga } \\
\text { (Female) }\end{array}$} & & \multicolumn{2}{|c|}{$\begin{array}{l}\text { Budi } \\
\text { (Male) }\end{array}$} & \multicolumn{2}{|c|}{$\begin{array}{c}\text { Bunga } \\
\text { (Female) }\end{array}$} & \\
\hline & & n & $\%$ & $\mathbf{n}$ & $\%$ & & $\mathrm{n}$ & $\%$ & $\mathbf{n}$ & $\%$ & \\
\hline Ability to & Correct & 52 & $28 \%$ & 63 & $33 \%$ & \multirow{3}{*}{0,289} & 39 & $21 \%$ & 53 & $27,7 \%$ & \multirow{3}{*}{0,125} \\
\hline \multirow[t]{2}{*}{ Recognize } & Incorrect & 134 & $72 \%$ & 128 & $67 \%$ & & 147 & $79 \%$ & 138 & $72,3 \%$ & \\
\hline & Total & 186 & $100 \%$ & 191 & $100 \%$ & & 186 & $100 \%$ & 191 & $100 \%$ & \\
\hline \multirow{9}{*}{$\begin{array}{l}\text { Ability to } \\
\text { Identify the } \\
\text { Cause of } \\
\text { Mental } \\
\text { Health } \\
\text { Problem }\end{array}$} & Correct & & & & & & & & & & \multirow{9}{*}{0,411} \\
\hline & Stress or Pressure & 116 & $62,4 \%$ & 133 & $69,9 \%$ & \multirow{8}{*}{0,012} & 67 & $36 \%$ & 79 & $41,4 \%$ & \\
\hline & Environmental Factors & 7 & $3,8 \%$ & 17 & $8,9 \%$ & & 47 & $25,3 \%$ & 33 & $17,3 \%$ & \\
\hline & Biological Factors & 5 & $2,7 \%$ & 2 & $1 \%$ & & 15 & $8,1 \%$ & 21 & $11 \%$ & \\
\hline & Incorrect & & & & & & & & & & \\
\hline & Personal Weakness & 49 & $26,3 \%$ & 27 & $14,1 \%$ & & 28 & $15,1 \%$ & 29 & $15,2 \%$ & \\
\hline & Trauma & 3 & $1,6 \%$ & 7 & $3,7 \%$ & & 19 & $10,2 \%$ & 16 & $8,4 \%$ & \\
\hline & Others & 6 & $3,2 \%$ & 5 & $2,6 \%$ & & 10 & $5,4 \%$ & 13 & $6,8 \%$ & \\
\hline & Total & 186 & $100 \%$ & 191 & $100 \%$ & & 186 & $100 \%$ & 191 & $100 \%$ & \\
\hline
\end{tabular}


Positive attitude toward Mental Health Problems

\section{Correct}

\begin{tabular}{lllll}
$\begin{array}{l}\text { Recommend help } \\
\text { Salah } \\
\text { Does not recommend help }\end{array}$ & 153 & $82,3 \%$ & 173 & $89,7 \%$ \\
\hline Total & 186 & $100 \%$ & 191 & $100 \%$ \\
\hline & & & &
\end{tabular}

\begin{tabular}{lllll}
182 & $97,8 \%$ & 187 & $97,9 \%$ \\
\hline & 4 & $2,2 \%$ & 4 & $2,1 \%$ \\
\hline 186 & $100 \%$ & 191 & $100 \%$
\end{tabular}

3) Mental health literacy on depression based on the gender of vignette characters

In the aspect of ability to recognize depression, Budi was recognized as being depressed by $28 \%$ of the respondents, while Bunga by 33\% of the respondents. In the aspect of knowledge about mental disorders, it is known that biological factors, personal weaknesses, and other factors are believed to be the cause of depression in male characters while stress or pressure, environmental factors, and trauma are more believed to be causes of depression in female characters. While in the aspect of positive attitude towards mental disorders, $82.3 \%$ of respondents thought that Budi need to get help from experts and $90.6 \%$ of respondents thought that Bunga need to get help from mental health experts.

Chi-square test results showed no differences in recognition of depression based on the gender of the character. However, there is a difference between knowledge of the causes $(\mathrm{p}=.012 ; \mathrm{p} \leq$ $.05)$ and expert help recommendations for depression $(p=.018 ; p \leq 0.05)$ based on the gender of the vignette characters.

4) Mental health literacy on schizophrenia based on the gender of vignette characters

In the aspect of ability to recognize depression, Budi was recognized as being depressed by $21 \%$ of the respondents, while Bunga by $27.7 \%$ of the respondents. In the aspect of knowledge about mental disorders, the results show that stress, environmental factors, and personal weaknesses are the three factors most widely believed to be the cause of schizophrenia, on both Budi and Bunga characters. While in the aspect of positive attitude towards mental disorders, as many as $97.8 \%$ of respondents thought Budi need to get help from experts and $97.9 \%$ of respondents thought that Bunga need to get help from mental health experts.

Chi-square test results showed no differences in recognition, knowledge about the causes of schizophrenia, as well as a positive attitude towards expert assistance based on gender of the vignette characters.

\section{Discussion}

The results show that there is no difference in the ability to recognize depression and schizophrenia based on the gender of respondents and character in the vignette. The results of the study revealed different results from most of the previous studies which suggests that women have better recognition abilities compared to men (Reavley, McCann, \& Jorm, 2012; Cotton, et al., 2006; Gibbons, Thorsteinsson, \& Loi, 2015). However, this study is in line with the results of the study of Marcus and Westra (2012) which states that there are no striking differences in terms of recognition and general mental health knowledge between men and women.

The results are also not in line with the opinion of Hadjimina and Furnham (2017) which states that there are differences in recognition of mental disorders among male and female sufferers because some mental disorders have different prevalence in the two genders. For example, depression will be recognized more in female figures because the prevalence of depression is higher in women. Based on Hadjimina and 
Furnham (2017) assertion, we conclude that the lack of recognition for differences between male and female figures can occur because both versions of the vignette have the same description except the use of the name Budi and Bunga and the lack of depictions of situations that are more prototypically "masculine" or "feminine". For example, by including a description of the loss of interest in the hobby of sewing in women.

The absence of gender differences in recognition ability can also be influenced by the level of education of respondents (Bener \& Ghuloum, 2010), experience of contact with people with mental disorders (Lauber, et al., 2003), campus environment that stimulates more talk about mental disorders, mental health campaigns, also the media depiction that revealed mental disorders as a condition that can be experienced by anyone. The wider internet coverage and more openness of men to their health problems on the internet (Ellis, et al., 2013) can also be a realization that it is no less important for men to have awareness about mental health.

The second result is about differences in the identification of causes of mental disorders based on the gender of the respondents showing that there is no difference in the identification of causes of depression and schizophrenia based on the gender of the respondents. However, there are differences in the identification of causes of depression based on the gender of vignette figures.

Environmental factors and trauma are more clearly identified as causes of depression in female characters while biological factors and personal weaknesses are more pronounced in male figures. Respondents think that personal weakness is a cause of depression for men and this can be due to the existence of male gender roles which require them to be aggressive, physically and emotionally strong (Wong, 2016). Men who deviate from these expectations will experience interpersonal and intrapersonal conflicts. Therefore, showing emotion and mental helplessness is considered a form of personal weakness in men.

There is no difference in identifying the causes of schizophrenia. As with depression, stress or daily stress is also the most valued factor as a cause of schizophrenia, so are male and female respondents. This is in line with research by Jorm, et al. (1997b) that daily stress is the most valued factor as a cause of schizophrenia. Other results, namely biological factors, are more often assessed as causes of schizophrenia than depression, in line with the results of Jorm, et al. (1997b).

Further results show that there are differences in attitudes towards expert assistance in depression based on the gender of the respondent and the vignette figure. The differences in attitudes towards expert assistance in depression based on the gender of respondents and figures are in line with the research of Wang, et al (2007). Wang, et al. (2007: 447) argued that the existence of this gender difference might be related to the lower prevalence of depression in men and due to the lack of exposure to the disorder. Lack of exposure results in a lack of awareness and knowledge which can contribute to low levels of assistance seeking. The low level of seeking help can also be related to personal weaknesses that tend to be considered men as a cause of depression (Wang, et al., 2015). The search for emotional assistance for mental health problems for men is also a sign of weakness and is contradicted by masculinity as well as fears of stigma that can be a reason why men choose not to seek psychological help (Wong, 2016 and Holzinger, et al., 2012).

The pattern of seeking expert assistance for mental health problems in the campus environment is still hampered due to the influence of negative stigma 
(Vidourek, et al., 2014; Holland \& Wheeler, 2016) and lack of mental health literacy, let alone help for depression which is still widely associated with personal weakness. This is proven by the fact that there are still many respondents, especially men who consider expert assistance to be less important for depression.

Further results show that there is no difference in attitude towards expert assistance in schizophrenia based on the gender of respondents and vignette figures. Almost all respondents agreed if schizophrenics get expert assistance related to mental disorders suffered, both male and female figures. These results are consistent with Jorm, et al. (1997b) and Gibbons, Thorsteinsson, \& Loi (2015) studies which state that expert assistance is more positive for schizophrenics than depression. One logical reason is that depression is more common and is more often associated with non-medical conditions such as fatigue and stress whose handling does not require expert help, unlike schizophrenia which describes more severe and less common mental conditions (Jorm, et al, 1997b).

\section{Conclusion}

From this study we can conclude that there is no difference in the ability to recognize depression and schizophrenia based on the respondent's gender and the gender of the vignette figure. However, there are differences in knowledge about the cause of depression based on gender where the environmental factors and trauma are identified as a prominent cause of depression in female figures while biological factors and personal weaknesses are more pronounced in male figures. There are also differences in positive attitudes towards expert assistance for depression based on the gender of respondents and figures, where more male respondents do not recommend expert help and it is not necessary for male character to seek expert help for depression.

Based on these conclusions, we can give several suggestions: 1) For mental health experts, the results of the analysis showed that men are more likely not to recommend seeking expert help related to depression and this can be influenced by negative stigma embedded within the society, as it is considered a sign of weakness that indicates less masculinity. For this reason, men are needs to be specifically targeted in efforts to improve mental health literacy, to help them reach appropriate assistance, and to reduce the negative stigma surrounding men and mental disorder. 2) For the university, the campus environment is a place where students spend a lot of time. For this reason, the campus can be an ideal place for students to improve mental health literacy by conducting campaigns, interventions that involve reducing the negative stigma of mental disorders, designing a curriculum that can increase mental health awareness, as well as providing mental health facilities that can be reached by the students.

\section{References}

Atzmüller, C., \& Steiner, P.M. (2010). Experimental vignette studies in survey research. Methodology European Journal of Research Methods for the Behavioral and Social Sciences, 6(3), 128-138. doi:10.1027/1614-2241/a000014

Azwar, S. (2018). Metode Penelitian Psikologi (Edisi II). Yogyakarta: Pustaka Pelajar.

Badan Penelitian dan Pengembangan Kesehatan. (2013). Riset Kesehatan Dasar (RISKESDAS) 2013. Kementerian Kesehatan, Jakarta. 
Bener, A., \& Ghuloum, S. (2010). Gender differences in the knowledge, attitude and practice towards mental health illness in a rapidly developing Arab society. International Journal of Social Psychiatry, 57(5), 480-486. doi:10.1177/0020764010374415

Biddle, L., Donovan, J., Sharp, D., \& Gunnell, D. (2007). Explaining nonhelp-seeking amongst young adults with mental distress: a dynamic interpretive model of illness behavior. Sociology of Health \& Illness, 29(7), 983-1002. doi:10.1111/j.1467-

9566.2007.01030.x

Chang, C. (2008). Increasing mental health literacy via narrative advertising. Journal of Health Communication, 13 , $37-55$. doi:10.1080/10810730701807027

Cotton, S.M., Wright, A., Harris, M.G., \& Jorm, A.F. (2006). Influence of gender on mental health literacy in young Australians. Australian and New Zealand Journal of Psychiatry, 40, 790-796. doi:10.1080/j.14401614.2006.01885.x

Diaz-Granados, N., \& Stewart, D.E. (2007). Using a gender lens to monitor mental health. International Journal of Public Health, 52, 197198. doi:10.1007/s00038-007-02172

Ellis, L. A., Collin, P., Hurley, P. J., Davenport, T. A., Burns, J. M., \& Hickie, I. B. (2013). Young men's attitudes and behaviour in relation to mental health and technology: Implications for the development of online mental health services. BMC Psychiatry, 13, 119. doi:10.1186/1471-244X-13-119.

Fakih, M. (2013). Analisis Gender \& Transformasi Sosial. Yogyakarta: Pustaka Pelajar.
Farrer, L., Griffiths, K.M., Leach, L.S., \& Christensen, H. (2008). Age differences in mental health literacy. BMC Public Health, 8. doi:10.1186/1471-2458-8-125

Furnham, A., \& Swami, V. (2018). Mental health literacy: A review of what it is and why it matters. International Perspectives in Psychology: Research, Practice, Consultation, 7(4), 240-257. doi:10.1037/ipp0000094

Gibbons, R.J., Thorsteinsson, E.B., Loi, N.M. (2015). Beliefs and attitudes towards mental illness: an examination of the sex differences in mental health literacy in a community sample. PeerJ, 3, e1004. doi:10.7717/peerj.1004

Hadjimina, E., \& Furnham, A. (2017). Influence of age and gender differences on mental health literacy of anxiety disorders. Psychiatry Research, 251, 8-13. doi:10.1016/j.psychres.2017.01.089

Holland, D., \& Wheeler, H. (2016). College student stress and mental health: examination of stigmatic views on mental health counseling. Michigan Sociological Review, 30, 16-34.

Holzinger, A., Floris, F., Schomerus, G., Carta, M. G., \& Angermeyer, M. C. (2012). Gender differences in public beliefs and attitudes about mental disorder in western countries: A systematic review of population studies. Epidemiology and Psychiatric Sciences, 21, 73-85. doi:10.1017/s2045796011000552

Hox, J.J., Kreft, I.G.G., \& Hermkens, L.J. (1991). The Analysis of Factorial Surveys. Sociological Methods \& Research, 19, 493-510. doi:10.1177/0049124191019004003 
Hunt, J., \& Eisenberg, D. (2010). Mental health problems and help-seeking behavior among college students. Journal of Adolescent Health, 46, 310.

doi:10.1016/j.jadohealth.2009.08.00 8

Jorm, A.F., Korten, A.E., Jacomb, P.A., Christensen, H., Rodgers, B., \& Pollitt, P. (1997a). "Mental health literacy": a survey of the public's ability to recognise mental disorders and their beliefs about the effectiveness of treatment. The Medical Journal of Australia, 166(4). doi:10.5694/j.13265377.1997.tb140071.x

Jorm, A.F., Korten, A.E., Jacomb, P.A., Christensen, H., Rodgers, B., \& Pollitt, P. (1997b). Public beliefs about causes and risk factors for depression and schizophrenia. Social Psychiatry and Psychiatric Epidemiology, 32, 143-148. doi:10.1007/BF00794613

Jorm, A.F. (2012). Mental health literacy: Empowering the community to take action for better mental health. American Psychologist, 67(3), 1-13. doi:10.1037/a0025957

Lauber, C., Nordt, C., Falcato, L., \& Rössler, W. (2003). Do people recognise mental illness? Factors influencing mental health literacy. European Archives of Psychiatry and Clinical Neurosciences, 253, 248-251. doi:10.1007/s00406-0030439-0

Leighton, S. (2010). Using a vignettebased questionnaire to explore adolescents' understanding of mental health issues. Clinical Child Psychology and Psychiatry, 15(2) 231-250. doi:10.1177/1359104509340234

Marcus, M., \& Westra, H. (2012). Mental health literacy in Canadian young adults: results of a national survey. Canadian Journal of Community Mental Health, 31(1). doi:10.7870/cjcmh-2012-0002

Novianty, A., \& Hadjam, M.N.R. (2017). Literasi kesehatan mental dan sikap komunitas sebagai prediktor pencarian pertolongan formal. Jurnal Psikologi, 44(1), 50-65. doi:10.22146/jpsi.22988

Pangkalan Data Pendidikan Tinggi Kementerian Riset, Teknologi Dan Pendidikan Tinggi. https:/ / forlap.ristekdikti.go.id. Accessed 23 March 2019.

Reavley, N., McCann, T., \& Jorm, A.F. (2012). Mental health literacy in higher education students. Early Intervention in Psychiatry, 6, 45-52. doi:10.1111/j.1751-

7893.2011.00314.x

Vidourek, R., King, K., Nabors, L., Lynch, A., \& Merianos, A. (2014). College students' perceived confidence in mental health help-seeking. International Journal of Mental Health Promotion, 16(2), 83-90. doi:10.1080/14623730.2014.892257

Wang, J., Adair, C., Fick, G., Lai, D., Evans, B., Perry, B.W., Jorm, A., Addington, D. (2007). Depression literacy in Alberta: Findings from a general population sample. The Canadian Journal of Psychiatry, 52(7), 442-449. doi:10.1177/070674370705200706

Wong, K. (2016). Gender differences in mental health literacy of university students. Western Undergraduate Psychology Journal, 4(1). 